Part of Journal of Research of the National Bureau of Standards, Volume 24, March 1940

\title{
REDUCING POWERS OF VARIOUS SUGARS WITH ALKALINE COPPER-CITRATE REAGENT
}

\author{
By Horace S. Isbell, William W. Pigman, and Harriet L. Frush
}

\begin{abstract}
Scales' method for the determination of reducing sugars was modified by increasing the boiling time, and reducing values of 32 sugars were determined at various concentrations. The method as modified provides a very simple, convenient means for the quantitative determination of the various sugars. A comparison of the reducing values of different sugars reveals that the configurations of carbons 3,4 , and 5 have marked effect on the reducing values, but that the configuration of carbon 2 has little influence. Sugars in which the hydroxyl on carbon 3 is trans to the hydroxyls on carbons 4 and 5 have the highest reducing powers, while those which have cis hydroxyls on carbons 3 and 4 have lower reducing values. When the glycosidic union of a disaccharide is on carbon 3 , the molecular reducing power is less than that of the monosaccharide corresponding to the reducing part of the molecule; if the glycosidic union is on carbon 4, the molecular reducing power is about 1.4 that of the corresponding monosaccharide, and if on carbon 6 , the molecular reducing power is about 1.2 that of the corresponding monosaccharide. The effect of barium bromide on the reducing powers of the sugars varies with the experimental conditions. Under the conditions used in this investigation the presence of 6.5 percent of barium bromide lowers the reducing value by approximately 4 percent.
\end{abstract}

\section{CONTENTS}

Tharacteristios of the method

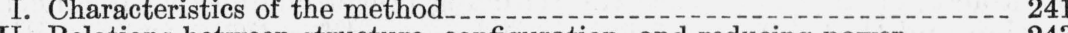

II. Relations between structure, configuration, and reducing power_._. 243

III. Effect of barium bromide on the reducing power

IV. Method for making sugar determinations

V. References_._. 246

\section{CHARACTERISTICS OF THE METHOD}

In the course of an investigation conducted in this laboratory $[1,2]^{1}$ on the oxidation of the sugars, it was necessary to adopt a method for determining reducing sugars which is simple and requires relatively small samples. These requirements are met by a method described by Scales, in which the cuprous oxide formed by the reduction of alkaline copper-citrate reagent is titrated with iodine $[3,4]$. According to the original method the sugar solution $(10 \mathrm{ml})$ is mixed with $20 \mathrm{ml}$ of the copper reagent, brought to boiling in 4 minutes, and boiled for 3 minutes. After cooling the solution, aqueous acetic acid, an excess of

\footnotetext{
1 Figures in brackets indicate the literature references at the end of this paper.
} 
$0.04 \mathrm{~N}$ iodine, and aqueous hydrochloric acid are added. The excess iodine is then titrated with sodium thiosulfate. According to Scales, each milliliter of $0.04 \mathrm{~N}$ iodine is equivalent to approximately 1.12 $\mathrm{mg}$ of dextrose. In our experience the value depends slightly on the concentration, so that it is necessary to use factors which vary with the amount of sugar in the sample. The factor, or sugar equivalent, is merely the number of milligrams of anhydrous sugar corresponding to $1 \mathrm{ml}$ of $0.04 \mathrm{~N}$ iodine under the conditions of the measurement.

When the method as described by Scales was applied to certain sugars in the presence of barium bromide, small variations in the boiling time gave erratic results. This appeared to be due to incomplete reduction caused by the retarding effect of barium bromide on the reaction. The difficulty was largely overcome by increasing the time of boiling to 6 minutes. Even when barium bromide is not present, the longer boiling time (especially for certain sugars) gives more uniform results. Notwithstanding this improvement, variations in the technique used in cooling the reduced copper solution and in adding the reagents affect the titration, so that different workers obtain slightly different factors. For this reason each investigator should determine his own factors whenever possible by following the same procedure with known quantities of the sugar under investigation.

Table 1 shows the variation of the dextrose factor with size of sample. Measurements were made according to the method described on page 245 , by three different observers, each of whom made three determinations at each concentration. Application of the "least-squares principle" to the data given in table 1 gives the following equation:

$$
f=1.0511+0.0021 C+0.000086 C^{2},
$$

in which $f$ is the factor for glucose and $C$ is the titration in milliliters of $0.04 N$ iodine solution.

These measurements and the measurements with other sugars, given in table 2 , clearly show that the reducing power changes with concentration and that different factors must be used for different quantities of sugar.

TABLE 1.-Variation of dextrose factors with samples of different sizes

\begin{tabular}{|c|c|c|c|c|c|c|}
\hline \multirow{3}{*}{$\begin{array}{l}\text { Milli- } \\
\text { grams of } \\
\text { dextrose }\end{array}$} & \multirow{3}{*}{$\begin{array}{c}\text { Milliliters } \\
\text { of } 0.04 N \\
\text { iodine solu- } \\
\text { tion }\end{array}$} & \multicolumn{5}{|c|}{ Sugar factors } \\
\hline & & \multicolumn{3}{|c|}{ Observer } & \multirow{2}{*}{ Average } & \multirow{2}{*}{$\begin{array}{l}\text { Calculated } \\
\text { from eq } 1\end{array}$} \\
\hline & & $A$ & $B$ & $C$ & & \\
\hline $\begin{array}{r}5 \\
10 \\
15 \\
20 \\
25\end{array}$ & $\begin{array}{r}4.69 \\
9.30 \\
13.72 \\
17.92 \\
21.93\end{array}$ & $\begin{array}{l}1.078 \\
1.078 \\
1.101 \\
1.123 \\
1.146\end{array}$ & $\begin{array}{l}1.066 \\
1.074 \\
1.096 \\
1.115 \\
1.148\end{array}$ & $\begin{array}{l}1.055 \\
1.073 \\
1.083 \\
1.110 \\
1.127\end{array}$ & $\begin{array}{l}1.067 \\
1.075 \\
1.093 \\
1.116 \\
1.140\end{array}$ & $\begin{array}{l}1.063 \\
1.078 \\
1.096 \\
1.116 \\
1.139\end{array}$ \\
\hline
\end{tabular}


TABLE 2.-Factors for various sugars for use with the modified Scales method ${ }^{1}$

\begin{tabular}{|c|c|c|c|c|c|c|c|c|c|}
\hline \multirow{2}{*}{ Sugar } & \multicolumn{4}{|c|}{$\begin{array}{l}\text { Milligrams of anhydrous } \\
\text { sugar per milliliter of } 0.04 \\
N \text { iodine }\end{array}$} & \multirow{2}{*}{ Sugar } & \multicolumn{4}{|c|}{$\begin{array}{l}\text { Milligrams of anhydrous } \\
\text { sugar per milliliter of } 0.04 \\
N \text { iodine }\end{array}$} \\
\hline & $\begin{array}{l}5-\mathrm{ml} \\
\text { titer }\end{array}$ & $\begin{array}{c}10-\mathrm{ml} \\
\text { titer }\end{array}$ & $\begin{array}{c}15-\mathrm{ml} \\
\text { titer }\end{array}$ & $\begin{array}{c}20-\mathrm{ml} \\
\text { titer }\end{array}$ & & $\begin{array}{l}\text { 5-ml } \\
\text { titer }\end{array}$ & $\begin{array}{c}\text { 10-ml } \\
\text { titer }\end{array}$ & $\begin{array}{c}15-\mathrm{ml} \\
\text { titer }\end{array}$ & $\begin{array}{l}20-\mathrm{ml} \\
\text { titer }\end{array}$ \\
\hline $\begin{array}{l}\text { l-Arabinose } \\
\text { Cellobiose }\end{array}$ & 1. 078 & 1.092 & 1.107 & 1.127 & Lactose_. & 1.426 & 1.434 & 1.445 & 1.462 \\
\hline$d$-Fruetos & 1.040 & $\begin{array}{l}1.383 \\
1.050\end{array}$ & $\begin{array}{l}1.095 \\
1.078\end{array}$ & $\begin{array}{l}1.410 \\
1.097\end{array}$ & $d$-Lyxose & & $\begin{array}{l}1.407 \\
0.994\end{array}$ & $\begin{array}{l}1.471 \\
1.006\end{array}$ & 1.024 \\
\hline$l$-Fucose & & 1. 201 & 1.235 & & Maltose. & 1.479 & 1.471 & 1.485 & 1.497 \\
\hline$d$-Galactose & 1. 215 & 1. 223 & 1. 240 & 1. 267 & $d$ - $\alpha$-Mannohepto & & 1.310 & 1. 328 & \\
\hline 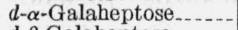 & & 1. 261 & 1.292 & -- & $d-\beta$-Mannoh & & 1.312 & 1.329 & \\
\hline$d-\beta-$ & & 1. 259 & 1. 283 & & d-Mannose & 1.075 & 1.087 & 1.103 & 1.126 \\
\hline Gentiobiose & & 1.717 & 1. 731 & 1.755 & Melibiose & 1.747 & 1.757 & 1.769 & - \\
\hline$d$ - $\alpha$-Glucoheptose & & 1. 291 & 1.313 & & Neolactose. & 1.427 & 1.433 & 1.440 & 1.451 \\
\hline$-\beta-G$ & & 1. 318 & 1.341 &.- & l-Rhamnose & 100 & 0.973 & 0.999 & - \\
\hline$d$-Glucose & 1.067 & $\begin{array}{l}1.20 \\
1.075\end{array}$ & $\begin{array}{l}1.022 \\
1.093\end{array}$ & 1.116 & l-Sorbose.... & 1.049 & $\begin{array}{l}1.065 \\
1.171\end{array}$ & $\begin{array}{l}1.083 \\
1.182\end{array}$ & 1. 106 \\
\hline 4- $\beta$-G lu co sido-man- & & & & & $d$-Talo & & 1. 224 & 1. 240 & \\
\hline & & & 1. 360 & 1.392 & Turanos & & 2. 691 & 2.714 & 1000 \\
\hline $\begin{array}{l}d-\alpha-G i \\
d-\beta-G u\end{array}$ & & $\begin{array}{l}1.291 \\
1.318\end{array}$ & $\begin{array}{l}1.312 \\
1.341\end{array}$ & $-\cdots$ & a-xylose....- & 0.996 & 1.007 & $\begin{array}{l}1.021 \\
1.082\end{array}$ & $\begin{array}{l}1.040 \\
1.095\end{array}$ \\
\hline d-Gulose. & 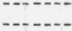 & 1.152 & 1.170 & $-\cdots$ & & & & & \\
\hline
\end{tabular}

1 The factors given in this table are the averages of the values obtained in measurements conducted in this laboratory over a period of 8 years. Each value represents not less than 3 determinations. The individual determinations by the same operator did not vary over 1 percent, but the results of different operators varied by as much as 2 percent.

\section{RELATIONS BETWEEN STRUCTURE, CONFIGURATION, AND REDUCING POWER}

The reducing values obtained with asymmetric reagents, such as the copper $d$-tartrate solution, depend on the configuration of the reagent as well as on the configuration of the sugar and differ for enantiomorphic sugars $[5,6]$. Since the alkaline copper-citrate reagent does not contain an asymmetric substance, it gives like reducing values for enantiomorphic isomers, and is particularly suitable for studying the relationship between configuration and reducing power. Since copper reagents buffered with sodium carbonate and bicarbonate oxidize the sugars more slowly than those containing sodium hydroxide [7], the reducing values depend upon the copper reagent used and upon the experimental conditions. The relative reducing powers observed for a series of sugars under one set of conditions with one reagent may differ widely from those found under different conditions with another reagent.

The various sugars under strictly comparable conditions reduce different quantities of copper. It may be observed by comparing the reducing values given in table 3 that epimeric sugars give approximately like reducing values - that is, the configuration of carbon 2 does not materially influence the reducing power. The similarity of epimeric sugars probably arises from the rapidity with which they revert to the common enolic form. Since the groups about carbons 3,4 , and 5 are held more firmly, sugars which differ in the configuration of these carbons are not interconvertible in the alkaline solution and exhibit characteristic properties. Sugars in which the hydroxyl on carbon 3 is trans to the hydroxyls on carbons 4 and 5 give the highest reducing powers, while sugars which have cis hydroxyls on carbons 3 and 4 give lower reducing values. The differences in the values for lactose, maltose, cellobiose, and turanose show that the configuration of the nonreducing component in the disaccharide $210560-40-2$ 
molecule influences the reducing power and that the reducing power of the disaccharide may be higher or lower than that of the reducing sugar component. If the glycosidic union is on carbon 3, as in turanose, the molecular reducing power is less than that of the corresponding monosaccharide. If the glycosidic union is on carbon 4, the molecular reducing power is about 1.4 that of the corresponding monosaccharide; and if the glycosidic union is on carbon 6 , the molecular reducing power is about 1.2 that of the corresponding monosaccharide. It may be observed from the results given in table 4 that the molecular reducing powers of the pentoses are slightly lower and of the heptoses slightly higher than the molecular reducing powers of the corresponding hexoses.

TABLE 3.-Relative molecular reducing powers ${ }^{1}$ (modified Scales method)

\begin{tabular}{|c|c|c|c|}
\hline Sugar & $\begin{array}{l}\text { Sample: } \\
\text { anhydrous } \\
\text { sugar in } \\
10 \mathrm{ml}\end{array}$ & $\begin{array}{l}0.04 N \\
\text { iodine } \\
\text { solution } \\
\text { consumed } \\
\text { by } \mathrm{Cu}_{2} \mathrm{O}\end{array}$ & $\begin{array}{l}\text { Relative } \\
\text { molecular } \\
\text { reducing } \\
\text { powers: } \\
\text { glucose }=1\end{array}$ \\
\hline $\begin{array}{l}d \text {-Glucose } \\
d \text {-Mannose-_- } \\
d \text {-Fructose } \\
\text { b-Rhamnose }\end{array}$ & \begin{tabular}{l|}
$m g$ \\
15 \\
15 \\
15 \\
13.7
\end{tabular} & $\begin{array}{l}m l \\
13.7 \\
13.6 \\
13.9 \\
13.8\end{array}$ & $\begin{array}{l}1.00 \\
0.99 \\
1.01 \\
1.01\end{array}$ \\
\hline $\begin{array}{l}d \text {-Galactose } \\
d \text {-Talose } \\
l \text {-Fucose }\end{array}$ & $\begin{array}{l}15 \\
15 \\
13.7\end{array}$ & $\begin{array}{l}12.2 \\
12.2 \\
11.4\end{array}$ & $\begin{array}{r}0.89 \\
.89 \\
.83\end{array}$ \\
\hline $\begin{array}{l}d \text {-Gulose } \\
\text { l-Sorbose-Arabinose- } \\
l \text {-Ribose } \\
d \text {-Ribose } \\
d \text {-Xylose } \\
d \text {-Lyxose }\end{array}$ & \begin{tabular}{l|}
15 \\
15 \\
12.5 \\
12.5 \\
12.5 \\
12.5 \\
12.5
\end{tabular} & $\begin{array}{l}12.9 \\
12.8 \\
11.4 \\
11.7 \\
11.7 \\
12.4 \\
12.6\end{array}$ & $\begin{array}{l}.94 \\
.93 \\
.83 \\
.85 \\
.85 \\
.91 \\
.92\end{array}$ \\
\hline 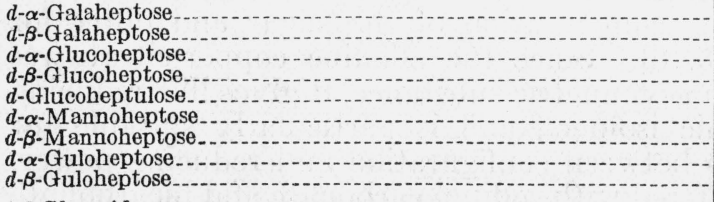 & $\begin{array}{l}17.5 \\
17.5 \\
17.5 \\
17.5 \\
17.5 \\
17.5 \\
17.5 \\
17.5 \\
17.5\end{array}$ & $\begin{array}{l}13.6 \\
13.7 \\
13.6 \\
13.1 \\
13.3 \\
13.2 \\
13.2 \\
13.4 \\
13.1\end{array}$ & $\begin{array}{r}.99 \\
1.00 \\
0.99 \\
.96 \\
.97 \\
.96 \\
.96 \\
.98 \\
.96\end{array}$ \\
\hline $\begin{array}{l}\text { 4- } \beta \text {-Glucosido-mannose } \\
\text { 4- } \beta \text {-Glucosido-glucose (cellobiose) } \\
\text { 4- } \alpha \text {-Glucosido-glucose (maltose) } \\
\text { 4- } \beta \text {-Galactosido-glucose (lactose) } \\
\text { 4- } \beta \text {-Galactosido-fructose (lactulose) } \\
\text { 4- } \beta \text {-Galactosido-altrose (neolactose) }\end{array}$ & \begin{tabular}{l|}
28.5 \\
28.5 \\
28.5 \\
28.5 \\
28.5 \\
28.5
\end{tabular} & \begin{tabular}{l|}
20.4 \\
20.2 \\
19.1 \\
19.5 \\
19.1 \\
19.7
\end{tabular} & $\begin{array}{l}1.49 \\
1.47 \\
1.39 \\
1.42 \\
1.39 \\
1.44\end{array}$ \\
\hline $\begin{array}{l}\text { 6- } \beta \text {-Glucosido-glucose (gentiobiose) } \\
6-\alpha \text {-Galactosido-glucose (melibiose) } \\
3-\alpha \text {-Glucosido-fructose (turanose) }\end{array}$ & $\begin{array}{l}28.5 \\
28.5 \\
28.5\end{array}$ & $\begin{array}{l}16.4 \\
16.1 \\
10.6\end{array}$ & $\begin{array}{l}1.20 \\
1.18 \\
0.77\end{array}$ \\
\hline
\end{tabular}

1 Ratio of the reducing power of the sugar to the reducing power of glucose.

TABLE 4.-Molecular reducing powers for configurationally related substances

\begin{tabular}{|cccc|c|c|c|}
\hline \multicolumn{3}{|c|}{ Configuration 1 } & \multicolumn{2}{c|}{ Average molecular reducing power } \\
\hline $\mathrm{C}_{2}$ & $\mathrm{C}_{3}$ & $\mathrm{C}_{4}$ & $\mathrm{C}_{5}$ & Pentoses & Hexoses & Heptoses \\
\hline \pm & $\mathbf{E}$ & \pm & \pm & 0.91 & 1.00 & 1.00 \\
\pm & \pm & \pm & \pm & .92 & 0.99 & 0.99 \\
\pm & \pm & \pm & \pm & .83 & .89 & .96 \\
\pm & \pm & \pm & \pm & .89 & .96 \\
\hline
\end{tabular}

1 The configurations of carbons $2,3,4$, and 5 are indicated by plus and minus signs according to whether the $\mathrm{OH}$ lies to the right or left when the formula is written in the conventional manner. For example. the configuration of $d$-glucose is indicated by +-++ . In the case of the pentoses, the sugar has been classified with the configurationally related hexose. Thus $d$-xylose, $d$-lyxose, $l$-arabinose, and $l$-ribose are placed with groups having the $(+)$ configuration for carbon 5 . 


\section{EFFECT OF BARIUM BROMIDE ON THE REDUCING POWER}

In harmony with prior observers, who noted that barium and calcium salts alter the reducing power of certain sugars, we found that the addition of either barium bromide or calcium chloride results in a marked decrease in the reducing power. The effect of barium bromide on the reducing power is shown by the data given in table 5, which was compiled from the results obtained in the course of our studies on the oxidation of the sugars with bromine water. Under the conditions of our measurements, and depending to some extent on the concentration of the sugar, the presence of 6.5 percent of barium bromide in the sugar solution lowers the reducing values by approximately 4 percent. If the time of boiling or any other experimental condition is altered, the effect may be larger or smaller.

TABLE 5.-Effect of barium bromide on the reducing values obtained by the modified Scales method

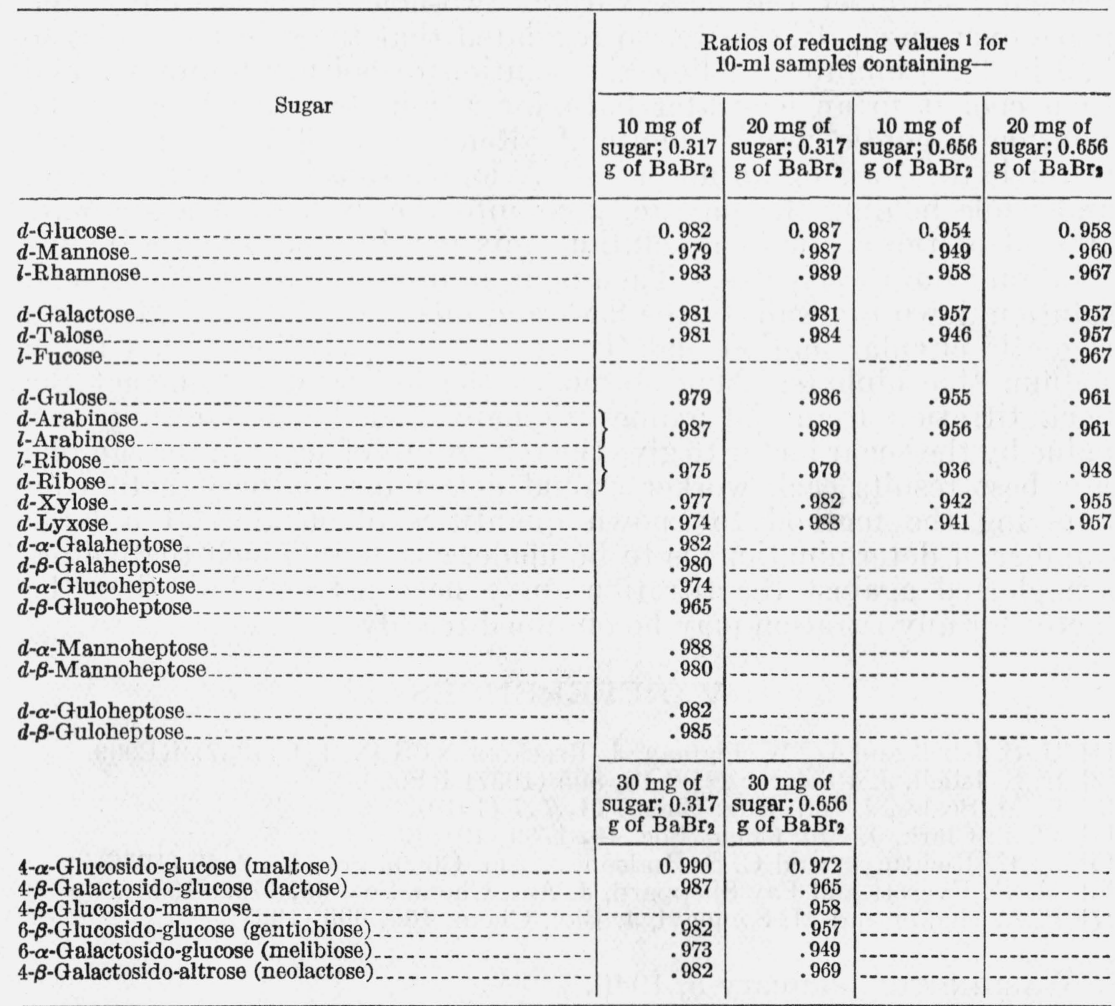

1 The ratio of the reducing value of the sugar in the presence of barium bromide to the reducing value of the sugar under like conditions in the absence of barium bromide.

\section{METHOD FOR MAKING SUGAR DETERMINATIONS}

Reagents needed:

1. Alkaline copper-citrate reagent. Dissolve $16 \mathrm{~g}$ of copper sulfate $\left(\mathrm{CuSO}_{4} \cdot 5 \mathrm{H}_{2} \mathrm{O}\right)$ in 125 to $150 \mathrm{ml}$ of water. Dissolve $150 \mathrm{~g}$ of sodium 
citrate $\left(2 \mathrm{Na}_{3} \mathrm{C}_{6} \mathrm{H}_{5} \mathrm{O}_{7} \cdot 11 \mathrm{H}_{2} \mathrm{O}\right){ }^{2}{ }^{2} 130 \mathrm{~g}$ of anhydrous sodium carbonate, and $10 \mathrm{~g}$ of sodium bicarbonate in about $650 \mathrm{ml}$ of water, while warming them slightly to accelerate solution. Combine the two solutions with stirring, make up to 1 liter, and filter.

2. $0.04 N$ solution of iodine containing 4 percent of potassium iodide.

3. $0.04 \mathrm{~N}$ sodium thiosulfate solution containing $0.1 \mathrm{~g}$ of sodium carbonate.

4. Hydrochloric acid solution containing $60 \mathrm{ml}$ of concentrated $\mathrm{HCl}$ per liter. liter.

5. Acetic acid solution containing $24 \mathrm{ml}$ of glacial acetic acid per

\section{Procedure:}

To $10 \mathrm{ml}$ of a solution containing 10 to $20 \mathrm{mg}$ of a monosaccharide (or about $30 \mathrm{mg}$ of a disaccharide) and contained in a 300-ml Erlenmeyer flask, add from a fast-draining pipette $20 \mathrm{ml}$ of the copper reagent. ${ }^{3}$ Stopper the flask with a two-hole rubber stopper and place over an electric heater so regulated that the solution comes to boil in $4 \pm 1 / 4$ minutes. Allow the solution to boil for 6 minutes and then cool it in an ice-water bath for $3 / 4$ minute while keeping the solution in gentle circular motion. ${ }^{4}$ Remove the flask from the icewater bath, draw up $25 \mathrm{ml}$ of $0.04 N$ iodine solution into a pipette, and while holding the pipette, pour into the flask from a graduate $100 \mathrm{ml}$ of the acetic acid solution, mix gently, and add the iodine solution from the pipette. Then pour $25 \mathrm{ml}$ of the hydrochloric acid solution down the walls of the flask and into the solution. Mix with a gentle circular motion and titrate the excess iodine with $0.04 \mathrm{~N}$ sodium thiosulphate, using starch as the indicator. ${ }^{5}$ Subtract the back titration from the iodine originally added and multiply this value by the sugar factor to give the milligrams of sugar in the sample. For best results each worker should determine his own factors by applying the method to known quantities of sugars. If a large number of determinations is to be made, charts in which the factors are plotted against the titrations may be constructed so that the factor for any titration may be obtained readily.

\section{REFERENCES}

[1] H. S. Isbell and W. W. Pigman, J. Research NBS 18, 141 (1937) RP969.

[2] H. S. Isbell, J. Research NBS 18, 505 (1937) RP990.

[3] F. M. Scales, J. Ind. Eng. Chem. 11, 747 (1919).

[4] W. P. Clark, J. Am. Chem. Soc. 40, 1759 (1918).

[5] N. K. Richtmyer and C. S. Hudson, J. Am. Chem. Soc. 58, 2540 (1936).

[6] M. R. Everett and Fay Sheppard, J. Am. Chem. Soc. 60, 1792 (1938).

[7] P. A. Shaffer and M. Somogyi, J. Biol. Chem. 100, 695 (1933).

Washington, January 5, 1940.

\footnotetext{
2 If $\mathrm{Na}_{3} \mathrm{C}_{6} \mathrm{H}_{5} \mathrm{O}_{7} \cdot 2 \mathrm{H}_{2} \mathrm{O}$ is used, $124 \mathrm{~g}$ should be taken.

3 The amount of sugar in the sample should be such that there is still an excess of the alkaline copper reagent after the oxidation.

4 For heating the samples a conical electric heater with all rings removed, and covered with an asbestoscentered wire gauze is recommended. It is connected in series with an adjustable resistance. A cylindrical shield should be placed around the flask during heating in order to protect it from drafts. When a number of determinations are to be made, a flask containing another sample may be placed on the electric heater as soon as the preceding sample has been removed. The time of heating is sufficient to allow for the titrations and for preparation of the next sample.

${ }_{8}$ The iodine solution added should be at least $4 \mathrm{ml}$ in excess. Before the excess iodine is titrated, the cuprous oxide precipitate must all be in solution. Because of the equilibrium between the iodide, cuprous, and cupric ions, it is necessary to follow the directions closely.
} 